Article

\title{
How Do the Support Networks of Older People Influence Their Experiences of Social Isolation in Care Homes?
}

\author{
Jennifer M. Ferguson \\ Faculty of Social Sciences, University of Stirling, UK; E-Mail: jennifer.ferguson1@stir.ac.uk
}

Submitted: 7 May 2021 | Accepted: 4 August 2021 | Published: 15 December 2021

\begin{abstract}
Understanding how to better support older people living in care homes is imperative for improving their wellbeing and quality of life. Despite this, little research has explored how support networks are structured and composed for individual residents. This study aimed to explore how, and by whom, residents felt they were supported, and how this support influenced their experiences of social isolation within the care home. The study included 36 residents from seven care homes located in the Scottish central belt in 2018. This article uses egocentric network analysis to analyse the structure and composition of the support networks, while a thematic analysis of qualitative interviews resulted in themes exploring how a resident's support network impacts their social isolation within the care home. Findings indicated that residents' most supportive alters were adult children, while staff members were only nominated as providing support in one third of support networks, despite most residents needing specialised care every day. Ambiguous relationships within residents' support networks lead to feelings of social isolation, as well as adding to residents' isolating behaviour. This suggests that national care frameworks, such as person-centred care frameworks, which advocate for coordinated support between residents, relatives, and staff are not being implemented effectively and that more needs to be done to break down barriers to inclusion for care home residents.
\end{abstract}

\section{Keywords}

care homes; meaningful relationships; social inclusion; social isolation; support networks

\section{Issue}

This article is part of the issue "In Good Company? Personal Relationships, Network Embeddedness, and Social Inclusion" edited by Miranda J. Lubbers (Autonomous University of Barcelona, Spain).

(C) 2021 by the author; licensee Cogitatio (Lisbon, Portugal). This article is licensed under a Creative Commons Attribution 4.0 International License (CC BY).

\section{Introduction}

Meaningful social relationships are consistently identified as essential to residents' wellbeing and quality of life (Roberts \& Bowers, 2015). Despite being surrounded by people every day, $22-42 \%$ of older people in care homes (CH) feel severely lonely, which is at least double the rate of their community-dwelling counterparts (Victor, 2012). Moving into a $\mathrm{CH}$ can lead to older people becoming isolated from the wider community, as well as having a more regulated social life through professional monitoring (Villar et al., 2021). Further, older people living in $\mathrm{CHs}$ have high levels of physical and cognitive impairment (Age UK, 2019), which can result in reduced social interaction, fewer meaningful relationships, and diminished wellbeing (Grenade \& Boldy, 2008). One of the main aims of the $\mathrm{CH}$ industry is to increase older people's social inclusion to improve and maintain their wellbeing (National Institute for Health and Care Excellence, 2019). However, how residents perceive their individual social support, and how a resident's support network may affect their social isolation is under-researched. This article examines how the support networks of older people can influence their social isolation, and therefore establish how the social inclusion of older people living in $\mathrm{CHs}$ can be improved.

\section{Background}

Social isolation is when an individual lacks a sense of belonging, engagement with others, has a minimal number of social contacts and has a deficit of quality 
relationships (Nicholson, 2009). A person's support network is a key component to alleviating social isolation through the provision of resources, opportunities for social participation and other supports which a resident might not be able to access otherwise (Langford et al., 1997), as well as providing an embeddedness in a network characterised through norms and trust (Coleman, 1988). Social support is a potential function of a social tie (Wellman, 1981), where a tie can be supportive or not. A social network may exist around an older person; however they may not consider all actors as supportive (Bowling, 1994). Therefore, perceived support may have a larger effect on experiences of social isolation and wellbeing. Moreover, a ties' strength may determine what type of support is provided. Granovetter (1973) defines a strong tie through intimacy, extended time spent together, reciprocity and emotional intensity. Therefore, while strong ties are more likely to provide emotional support, weaker ties are more likely to provide new information and instrumental support which a person may not have immediate access to. Forsman et al. (2011) found that ties to close friends and family were more important for older people than the support of weaker ties to formal life. Thus, a resident's experience of social isolation may be affected by what type of support is being provided and whether they consider that tie to we strong or not. Further, Cornwell et al. (2008) found that older people living in the community were likely to combat shrinking social networks (e.g., death of partners and peers) with higher engagement with neighbours and organised groups. This may be problematic for older people who move into $\mathrm{CHs}$ and away from communities in which they received a lot of social support through these groups. Given the importance of meaningful social relations for the wellbeing of older people living in $\mathrm{CHs}$, further examination of how these relations impact a resident's social isolation is warranted.

Research has explored how residents make and maintain relationships with staff (Canham et al., 2017), other residents (Abbott \& Pachucki, 2016), and family and friends (Cook, 2006). However, few use a network approach to explore how social relationships impact residents' inclusion and wellbeing. In one of the few network studies investigating this, Cheng (2009) looked at how many people were in the support networks of older people living in $\mathrm{CHs}$ in Hong Kong. Cheng found that residents nominated an average of 2.6 people in their network from whom they felt they could receive support, with only $20 \%$ nominating another person in the $\mathrm{CH}$, the majority of which being staff. This suggests that despite being surrounded by staff and peers, residents did not feel that they could receive support from them, or that they were important in their lives (Cheng, 2009).

In the UK, person-centred care (PCC) principles are synonymous with good quality care (Brooker \& Latham, 2015) and evidence suggests that $\mathrm{CHs}$ that follow PCC principles have a better culture of care and better staffresident relationships (Killett et al., 2016). PCC prin- ciples include recognising the individual needs of the person and acknowledging how their life experience and personality might impact their needs (Baker, 2015; Kitwood, 1997). Killett et al. (2016) provided evidence of better relationships between residents, staff, and relatives when staff knew the resident as an individual and showed that they really cared. This resulted in residents and relatives being more understanding of the staff's time and practice, increasing rapport and trust between all parties.

Close relationships are especially important for older people as they provide mutual trust and a sense of security and have been found to be far more important than more formal ties (Forsman et al., 2011). In particular, family and close friends help to maintain a resident's sense of identity through enabling staff get to know their relative (Davies \& Nolan, 2006).

More recent work on the blurring of strong and weak ties for older people suggests that "elastic ties" exist where the relationship between two people does not conform to either a strong or weak tie (Torres, 2019). For example, Torres (2019) documented how older people who did not know each other well would share personal details and stories regularly, as well as reciprocating emotional support; however, many did not know each other's name. Although these older people would not have nominated each other as confidents, they informally supported each other through regular social contact. Similarly in $\mathrm{CH}$ research, Canham et al. (2017) showed how staff who voiced "family-like" feelings toward residents built stronger, more positive relationships with residents, which resulted in residents feeling more included in $\mathrm{CH}$ communities. Thus, it is not clear how resident's may use their support networks, stronger (family and friends), and weaker (staff) ties, to gain support and improve their social connectedness.

Close relationships can also harbour tension and disagreement, which can lead to increased social isolation if this leads to barriers to support or a change in relationship. In this sense, close ties can be ambivalent, where ties are not simply conflicting or supportive, but are nuanced by acknowledging emotional closeness while harbouring tension between two people (Lüscher, 2002). Hillcoat-Nallétamby and Phillips (2011) show how relationships between older people and their families provide important support but may also express feelings of indifference or tension. They describe one such relationship where an adult daughter felt the social expectation of having to care for her mother, while their relationship was often difficult. Thus, the social connections of older people have the potential to be a key facilitator of social inclusion through meaningful relationships, the provision of support and resources, as well as cohesion and cooperation between supporting actors. However, ambiguity within relationships may result in barriers to support and additional social isolation for $\mathrm{CH}$ residents.

The complex nature of social connections leads us to ask how, and by whom, residents think they are 
supported in a $\mathrm{CH}$ environment, and how these supportive ties facilitate social inclusion? As such, this study aims to explore how $\mathrm{CH}$ residents' personal support networks impact their social isolation.

\section{Methodology}

Research design, data collection, and analysis were conducted by the author, a female researcher trained in social network analysis and qualitative methodologies. Data collection occurred between March and September 2018 in the Central Belt of Scotland.

\subsection{Sample}

$\mathrm{CH}$ s were recruited through the ENRICH Scotland network, an organisation connecting researchers with $\mathrm{CHs}$ wanting to participate in research (National Institute for Health Research, 2021). The project aimed to sample $\mathrm{CHs}$ from different areas of deprivation in the Scottish central belt, and under different ownerships (e.g., local authority/not for profit/private), in order to represent varying access to resources and support for residents.
Seven, out of $12 \mathrm{CHs}$ approached, agreed to help recruit residents as shown in Table 1.

The researcher asked $\mathrm{CH}$ managers to list residents who might have capacity to consent to research, and to consider anyone with mild to moderate cognitive impairment as potentially able to give consent to research. Thereafter the researcher assessed resident's capacity to give informed consent through a mental capacity assessment (Social Care Institute for Excellence, 2021). Eightyseven residents were approached across the seven $\mathrm{CHs}$ : 29 did not have capacity to consent, 17 declined to be interviewed, and 5 dropped out of the study. In total, 36 residents had the capacity to consent and agreed to be interviewed. Some participants had mild cognitive impairment (e.g., memory problems); however, all interviewed residents had the capacity to give informed consent throughout the interview process, which was established through a mental capacity assessment at the initial meeting and the principles of process consent throughout the research process (Dewing, 2007). As seen in Table 2, the majority of participants were female (81\%) and the average age of the participants was 87 years old, ranging between 72 and 100 .

Table 1. Care homes sample characteristics.

\begin{tabular}{lrccc}
\hline $\mathrm{CH}$ & SIMD $^{1}$ & Size (no. of beds) & Wider area & Funding type \\
\hline 1 & 7 & 68 & Greater Glasgow & Private \\
2 & 9 & 35 & Lothian & Not for profit \\
3 & 6 & 62 & Lanarkshire & Private \\
4 & 5 & 80 & Lanarkshire & Private \\
5 & 10 & 35 & Lothian & Private \\
6 & 9 & 63 & Lothian & Not for profit \\
7 & 1 & 66 & Greater Glasgow & Local authority \\
\hline
\end{tabular}

Note: ${ }^{1}$ The Scottish Index of Multiple Deprivation (SIMD) ranks small areas (data zones) from least (10) to the most deprived (1). For more information see Scottish Government (2016).

Table 2. Demographics of residents.

\begin{tabular}{clrr}
\hline & Category & $\mathrm{n}$ & $\%$ \\
\hline Gender & & 36 & \\
& Female & 29 & 81 \\
Funding category & Male & 7 & 19 \\
& Self-funded & 25 & 69 \\
& Partially funded & 6 & 17 \\
$\mathrm{CH}$ & Local authority funded & 5 & 14 \\
& 1 & 6 & 17 \\
& 2 & 6 & 17 \\
& 3 & 5 & 14 \\
& 4 & 5 & 22 \\
& 5 & 8 & 11 \\
& 6 & 4 & 2 \\
\hline
\end{tabular}




\subsection{Network Interview}

This article focuses on older people's perception of support, and how support affects their experience of social isolation. Social isolation can be defined through the objective measure of social connectedness and subjective perceived isolation (De Jong Gierveld \& Hagestad, 2006). Although this study captured the social connectedness of residents through their support networks, social isolation was captured through qualitative methods where residents would describe their perceived isolation within the $\mathrm{CH}$. As this study aims to capture a resident's perception of social isolation, it took an exchange approach to social support, where I aimed to capture a subset of supportive actors who would arguably have a greater effect on a resident's experience of isolation. During the interview, respondents were asked about who supports them, and if those people knew one another. House and Khan's (1985) definition was used as a framework for support, and therefore I chose five name-generator questions which reflected three types of support: instrumental support (ties that provide resources, money or assistance), emotional support (ties that offer love or nurturing), and informational support (ties that provide knowledge, advice, and information). This name-generator approach is intended to highlight different supportive actors, who may offer different types of support to the participant (McCallister \& Fischer, 1978). The name-generator questions used were:

1. Most people discuss important personal matters with other people. Who are the people with whom you discuss matters that are important to you?

2. Occasionally, people socialise with other people, for instance, they visit each other, go out for an outing or for a meal. Who are the people you really enjoy socializing with?

3. From time to time, people ask other people for advice when a major change occurs in their life, for instance, a change in location or a serious accident. Who are the people you usually ask for advice when such a major event occurs in your life?

4. Could you name anyone who has provided you with help recently?

5. Please list anyone who is especially close to you who you have not listed in one of the previous questions.

These questions allowed supportive alters from different social domains (White, 2008) to be nominated multiple times for different types of support (Crossley et al., 2015) and allowed the visualisation of a support network for each resident. Demographic information was collected about each alter, including their relation to the resident, and the resident was asked if alters knew each other to establish interrelationships. A network approach is appropriate as it goes beyond the single relationship between staff and resident, or family and resident. Instead, it tackles the embeddedness of social relations (Granovetter, 1985) by exploring how multiple relations interact and integrate (Holstein, 2014), which could be important for their wellbeing. Name-generator questions were restricted to five people per question, and some interviews were completed over two or three sessions to limit respondent fatigue (Abbott \& Pachucki, 2016). This created a visualisation of a support network, which starts with an ego (resident), their nominated supportive people (alters) and the connections between those alters (Crossley et al., 2015). In total, 229 alters were nominated by the 36 residents, with a range of 1-17 alters per network.

During the network data collection residents gave rich descriptions of their network and offered reasons why alters were more or less supportive than others. If this had not occurred already, residents were prompted to discuss their networks in more depth after the network structure was established, allowing them to explain complexities and relationships in their network. For example, I asked them questions about why they thought alters supported them in different ways, what sort of activities they did with these alters, and examples of when these alters had supported them and under what circumstances. All interviews were audio recorded and transcribed by the researcher.

\subsection{Analysis}

Egocentric network analysis was used to create descriptive statistics of the composition and structure of networks, followed by visualisations of each support network (Perry et al., 2018). By linking an edge-list, which is a list of all alters which are connected to the ego, and an alter attribute list, which is a list of attributes associated with the alters, through $\mathrm{R}$ software, the networks could be created, from which all visualisations and measures were derived. A thematic analysis of the qualitative transcripts was undertaken (Braun \& Clarke, 2020) using Nvivo. This was achieved by familiarising myself with the data (through completing interviews, transcribing, and rereading of transcripts), coding the data (by finding patterns and similarities between accounts), and building themes (through clustering codes into more meaningful wider patterns). A summary of themes has been displayed in Table 3 below and are discussed in the results section in this order. Themes are clustered by relation to resident as it was clear from the thematic analysis that residents treated these relations differently in terms of expectation and types of support provided, and thus different themes were apparent for these separate groups of relations.

Constructed themes were triangulated with the systematic patterns identified in the egocentric network analysis, resulting in a better understanding of how residents were supported and why residents turned to some alters over others. The use of meaningful and standardised name generator questions gave the structure and 
Table 3. Themes from thematic analysis clustered by relation.

\begin{tabular}{ll}
\hline Tie relation & Themes \\
\hline Family and friends & Meaningful family connections \\
& Providing multiple types of support \\
& The role of adult children \\
& Balancing reliance and autonomy \\
& Long term friendships \\
& Challenges of making new friends \\
& Gendered spaces and activities \\
& The absence of staff support \\
& Staff as safety net or service \\
& Time and resources \\
& Care home is not home \\
& Negative experiences \\
& Spending meaningful and extended time together \\
& Coordination and connection with family \\
\hline
\end{tabular}

composition of networks, while the qualitative description provided meaning and intent behind these connections. The qualitative data not only confirm the observed structures through triangulation and validation (Wald, 2014), but also contextualised them, and improved the interpretation of the network analysis results.

Ethical approval was granted by the University of Stirling General University Ethics Panel in January 2018 (reference GUEP292).

\section{Results}

It is important to emphasise that many residents had gone through extensive changes including increased physical and cognitive impairment, death of partners, siblings and friends, moving house, and sometimes moving to a new locality. Just one of these changes would have an impact on how someone would interact in their support network and wider community. However, for many residents many of these changes happened in quick succession. This often resulted in a shrinking of networks, where the number of people the older person could turn to for support became smaller. Due to the residents' increased physical or cognitive impairments, maintaining and making new contacts became more difficult resulting in greater feelings of social isolation. Also, residents were rarely allowed, or able, to leave the $\mathrm{CH}$ without a carer, except for few residents who had family members who were able to take them out for short excursions. Thus, for many residents, long-standing close ties were of acute importance given the potential shrinkage that had occurred through the events that led them to move into a $\mathrm{CH}$.

\subsection{Meaningful Family Connections}

Family ties were found to provide the most support to residents, as they not only accounted for the majority of alters $(53 \%)$, but also, were more likely to be nomi- nated for multiple types of support. Residents described how visits from family were the most meaningful part of their day, and how their family role was a large part of their identity. They were fathers, mothers, brothers, aunts, grandfathers, and great-grandmothers:

Well I think my life has meaning to my family, and to my grandchildren. I'm not sort of... isolated. My family are very interested to come and visit me, and they all do. (Resident 32, female)

Many residents felt that their families were the only people that mattered anymore, and without family, they felt they may be isolated. This was particularly evident as a third of residents only nominated family ties in their support networks.

\subsection{Providing Multiple Types of Support}

Network visualisations highlighted how family members were nominated for multiple types of support. However, it was also clear that the majority of networks only contained one or two alters who were nominated multiple times, and this included entirely family-based networks. These patterns can be viewed in the sociograms included in Figure 1, which shows each alter nominated for support and how many types of support an alter provided to the residents through the size of node. These highly supportive ties who are nominated for all domains of support are nearly always adult children of the residents.

\subsection{The Role of Adult Children}

Children not only provided more diverse and regular support than other nominated alters but were often the main coordinator for any contacts outside of the $\mathrm{CH}$ and staff. Children would often facilitate communication, arrange visits and outings, and act as an intermediary between the residents and their wider family: 


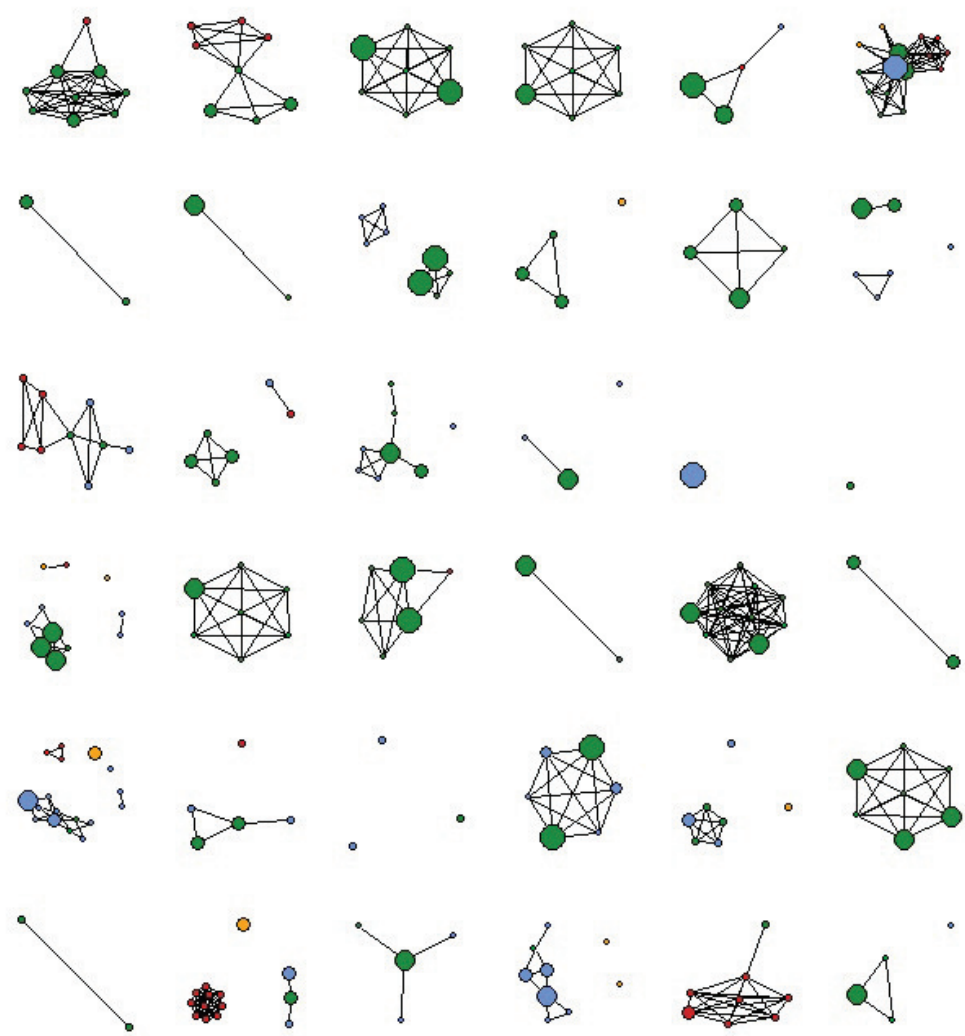

Figure 1. Support networks of 36 residents with relationship to ego in colour and number of support nominations as size of node.

I'm going to spend the weekend at her [daughter's] house-her son's house-and the rest of the family will come there to see me. (Resident 16, female)

Some children would also coordinate with the residents' previous community to ensure that the resident still felt connected to the place that they had lived before moving. For example, one daughter organised for her mother, who could no longer read, to receive a local "talking paper" (which was an mp3 file on a USB delivered by post that she could play through her digital radio) which updated her about her local community's news every week. This innovative method of engagement partially mitigated the issue that the resident was no longer able to travel to this community. However, for most residents, their families were more focused on activities in the $\mathrm{CH}$ or family visits, rather than engaging with the community that residents had previously lived in. For this reason, most residents' social interaction was restricted to family and those within the $\mathrm{CH}$.

\subsection{Balancing Reliance and Autonomy}

Family relations were sometimes complicated by the power imbalance between the resident and their children. Many residents still relied on family and friends for social contact and resources from outside of the $\mathrm{CH}$, as well as emotional support and transport.
With less engaged families, or those who visited less than the resident felt they should, residents would become frustrated:

I just get wee bit upset. My daughter... has done a tremendous lot for me, but she doesn't come much to take me out in a week....So I get a bit distressed at that. But I don't want to have a row with her. (Resident 31, female)

This was particularly difficult as residents were often trying to balance their perception that their family should want to be with them, with their concern that they were being too demanding of their families. Therefore, if this relationship became strained, some residents would concede to the family member's opinion or schedule, and avoid upset, in order to maintain the relationship. Thus, although residents voiced their appreciation for family members, some residents were very aware of the control that family members had on their lives while in the $\mathrm{CH}$ :

I'm always asking, "Please will you buy me a phone?" but I think she [daughter] thinks that I would be making a nuisance of myself by phoning up too often. But maybe l'll persuade her tomorrow. (Resident 54, female) 
This control sometimes resulted in residents feeling as though they were a burden, lacked autonomy and should restrict their requests to only those that were "necessary." This became especially apparent for residents who only nominated family members for support, as they did not seem able to talk to others about important decisions in their lives. Even during this study, some residents did not wish to participate without "permission" from their families first. This was not because they needed permission, but because they relied so heavily on them, they felt the need to ask for permission for all decisions in their lives. Therefore, families tended to have a lot of influence and control over their lives which could restrict residents' independence.

\subsection{Long-Term Friendships}

Only one resident did not have any family and only nominated one friend in their support network. This friend was incredibly important to the resident and provided almost every type of support. Friends were also much more important to residents whose families lived far away or did not have children.

I have to think of friends who come in-the same faithful people.... Obviously your friends are your family....The great value of them of course is that they've known me a long time. They knew you at home, what you were. Your home, your lifestyle, everything about you. (Resident 53, female)

Further, friendships were especially important for maintaining links with community or church groups. Although the $\mathrm{CHs}$ did facilitate church visits on rare special occasions, this was often not possible because of the lack of resources/staff needed to go every week:

I go [to church] every week. One of my friends [from her church] takes me to church every week, and she's very good. (Resident 24 , female)

Residents had to rely on friends or fellow church members for transport to the church, however for many residents this was not an option as they did not have the social connections to facilitate this.

\subsection{Challenges of Making New Friends}

Just over half of residents nominated a friend in their support network $(n=17)$, however none of these friendships were new connections with other residents. Participants suggested that making new friendships with other residents was difficult; in particular, if the other resident was living with advanced dementia. Some residents would express pity for people living with dementia, while others would make fun of people who had difficulty communicating:
They're so mentally disturbed that you can't really have a conversation. They're so beyond anything. You talk to them just to give them an interest. They just sit and stare in front of them. (Resident 32, female)

Residents noted that relationships with fellow residents had a negative impact on their day-to-day living due to awkwardness, dislike of being in their company, or resentment for the staff time they took up. Thus, residents who were interviewed felt that, rather than fellow residents forming a community around them, they could add to their isolation by making them more likely to spend time in their rooms; this had a negative impact on them pursuing interests and activities in the $\mathrm{CH}$. Moreover, the possibility of fellow residents dying dissuaded residents from forming friendships with others as they did not want to be hurt if they died. Thus, this added residents' isolating behaviour, by making them more likely to spend time in their rooms away from other residents and making them less likely to pursue interests and activities in the $\mathrm{CH}$.

\subsection{Gendered Spaces and Activities}

Further to this, men living in the $\mathrm{CH}$ seemed to be even less likely to make friends as many of the activities and communal areas were designed to please the majority of people, which were the females. For example, a lot of the activities were based around crafts, singing, baking and flower arranging. Despite this, $\mathrm{CH}$ did try to engage male residents, but often these were small gestures or outings aimed at the men in a group:

Interviewer: So you're away for pie and a pint today? Do they do that every week?

Respondent: No, only once in a while. Maybe once a fortnight. (Resident 13, male)

Further, male residents often felt "outnumbered" and therefore they felt they could not use communal areas, which were mainly female dominated.

And one time we were down there [lounge], me and the two other men, and we wanted to watch the football. But they [women] didn't want to, they all started [respondent makes moaning sounds]. (Resident 42, male)

Therefore, not only did men have less opportunities to make meaningful relationships with staff and fellow residents because there were less activities that appealed to them, but they sometimes felt excluded from communal areas, where they could potentially engage with different people. The male residents believed that this happened because these areas were often used for what most people wanted to do, and the majority were female residents. 
Thus, having long-term, close connections were frequently mentioned by residents as being important for support, however family were valued most by the majority of residents. Adult children, in particular, were emphasised as key to facilitating inclusion into the wider family and sometimes with residents' friends and wider community. However, power imbalances between residents and their children sometimes created tension and ambiguity in relationships, which left the residents feeling frustrated and with less autonomy. In general, friends seemed to play a smaller role in residents' support, however those who did not have family relied heavily on friends for support. Further, informal support between residents seemed minimal due to residents' reluctance to make friends with other residents, or, for men in particular, a lack of appropriate activities and space aimed at them to socialise.

\subsection{The Absence of Staff Support}

To reiterate, two thirds of the older people interviewed did not nominate a staff member for support and staff members accounted for only $17 \%$ of all alters nominated. Many of the residents interviewed had complex care needs and therefore needed a lot of care from staff on a day-to-day, or even hourly, basis. Thus, not nominating staff for a type of support such as "providing help" could be considered troubling considering the aim of a CH. Equally not nominating staff members for "socialising" when they live and work in the same space everyday may be concerning for care policies, such as PCC, which encourage meaningful relationships between staff and residents. Patterns in support and qualitative descriptions gave an indication of why residents were less likely to nominate staff, and how this may relate to their social inclusion in the $\mathrm{CH}$.

Although some residents felt they could nominate staff for support, the support they received from staff was more likely to be practical, rather than emotional support. Table 4 describes what proportion of the different types of support were given by what types of relationships. For example, for name-generator question 1, summarised as "Personal matters," $79.5 \%$ of the alters who made up those who would discuss personal matters with the resident were family.

\subsection{Staff as Safety Net or Service}

If we consider the type of support that staff members were nominated for, we can see that they were more likely to be nominated for providing help and as "other" close persons, which was a category used to capture alters which did not provide any of the previous supports but were still important to include in their support networks. This resonated with descriptions of staff relationships where residents treated the staff support as a service, or safety net, rather than an opportunity to build a relationship with that person:

The only person that I would definitely go to [for help] would be my son and my daughter. But if I fell, or something like that in here then I would need help then. And it would just be whoever was on duty because they're all very well-trained people. (Resident 32, female)

Some residents mentioned that although they could theoretically go to staff for support, they would likely never do this or only go to staff in an emergency. Resident 34 was one such example as she felt she could go to staff, however she did not want to include them on her list of people who supported her; instead, she talked about how she appreciated the staff "giving me my own space" and how she thought it was "important that you've always got someone in the background." When probed about the role of staff in their lives, they often talked about how they did not really know the staff or, as with Resident 34, they were a safety net that they never needed to use. Additionally, residents would discuss how they would prefer to go to family for any issues, staff were demoted to not being nominated because they had never had the need for their support in the resident's view.

\subsection{Time and Resources}

For other residents, there were not enough staff in the $\mathrm{CH}$ which resulted in staff not having enough time to socialise or help them effectively, which resulted in them isolating themselves in their rooms or feeling frustrated with staff:

Table 4. The proportion of types of support by relation to the resident.

What types of support are family, friends, staff and other types of ties providing? (\% of type of support)

\begin{tabular}{lccccc} 
& Personal matters & Socialise & Advice & Help & Other \\
\hline Family & $79.5 \%$ & $59.7 \%$ & $77.9 \%$ & $44.7 \%$ & $49.2 \%$ \\
Friends & $11.0 \%$ & $36.4 \%$ & $13.6 \%$ & $19.4 \%$ & $29.5 \%$ \\
Staff & $6.8 \%$ & $1.3 \%$ & $1.7 \%$ & $31.4 \%$ & $19.7 \%$ \\
Others & $2.7 \%$ & $2.6 \%$ & $6.8 \%$ & $4.5 \%$ & $1.6 \%$ \\
Total = n (\%) & $73(100 \%)$ & $77(100 \%)$ & $59(100 \%)$ & $67(100 \%)$ & $61(100 \%)$ \\
\hline
\end{tabular}


Either there is not enough staff or there is not enough time, or their time is not being used effectively. (Resident 53, female)

This discontentment with staff, or lack of staff, seemed to fuel residents' reluctance to rely on them for support.

\subsection{Care Home Is Not Home}

However, for some residents, not nominating staff for support seemed to stem from them not wanting to live in the $\mathrm{CH}$ or feeling they were only living in the $\mathrm{CH}$ to alleviate their family of their care. Thus, by not nominating staff, they were distancing themselves from staff and reiterating that they did not actually depend on the staff for support because they were only living there to make sure their families were not worrying or did not want to place the burden of their care on their families:

It's alright, Hen [Scottish term for girl], but it's not home but I won't ask my family to take me because, as I told you, I looked after my mother-in-law [and she remembers how taxing it was]. (Resident 16, female)

\subsection{Negative Experiences}

For some residents, not nominating staff or only nominating staff for practical support stemmed from negative experiences which left them deeply upset with how they had been treated:

I'm really miserable. Maybe I'm watching something on the telly and I'm asking to go [to the toilet] and they say "not now" or something like that. They don't take me....They don't have enough staff. I mean sometimes it's every day, or you ring the bell and they don't hear it, or they say they don't hear it. You've just got to wait. (Resident 44, female)

This meant that although residents knew they needed the help of staff on a day-to-day basis, they did not necessarily trust staff, or viewed them as a necessary support, rather than people they wanted to spend time with.

\subsection{Spending Meaningful and Extended Time Together}

Despite most residents only nominating staff for instrumental support, or not nominating them at all, there were some residents who did have an emotional connection with staff and did feel like they could rely on them. Of the few residents who had these positive relationships with staff, many only had this type of relationship with one staff member who was often characterised as good humoured, chatty and had worked in the $\mathrm{CH}$ a long time. These positive relationships were cultivated through spending extended periods of time not involving caring tasks. For example, taking the resident to see their local church or coordinating together to do some- thing purposeful around the $\mathrm{CH}$ :

And I help call round with Sasha [activities coordinator] quite a lot-she's great. She's a lovely person and she works so hard.... We'd been out at the cafe in the early afternoon. (Resident 31, female)

I'm always coming out with jokes with her [carer]. (Resident 18, male)

\subsection{Coordination and Connection With Family}

These emotionally supportive relationships were often characterised with a coordination of support with family members too. A typical example of this was when staff tried to interact with other family members who visited the resident:

Well, there was one day that they came in and [nurse] was bandaging me, and of course he [4 years old grandson] came in and he started watching and everything. And she said, "Are you going to help me Dr...?" And he said, "Oh yes." So he was bandaging me and bandaging me. Counting them up. Lovely boy. So he knows [nurse]. And they know her when he come to visit me. (Resident 41, female)

If the staff took time to get to know the resident's families, then the resident not only benefitted from a better relationship with staff, but they also felt that they could rely on staff and family to coordinate together:

Well, there was one at our table who was just a bit strange always, picking on things. And I wasn't very happy. But I went to Fiona [daughter]. And she and the staff sorted it. So I was moved tables to another table. And that was fine. (Resident 63, female)

Residents who felt that the staff knew their relatives seemed to have more trust in the staff and have a friendlier relationship. Thus, cultivating this relationship between staff and relatives could be very important for improving relations between residents and staff, as well as encouraging a supportive environment in the $\mathrm{CH}$ in general.

\section{Discussion}

$\mathrm{CH}$ residents should have the opportunity to be socially included with close relations and their wider community. However, this study has shown how the social relations that surround an older person can be pivotal to their support but also impact their experience of social isolation.

Analysis of support networks showed that older people living in $\mathrm{CHs}$ valued the support of family members more than any other type of tie, resonating with Forsman et al. (2011) describing how family ties provide a sense of security and trust for older people. Adult 
children were often nominated for multiple types of support, and residents described how children coordinated with staff, extended family, friends and sometimes wider community ties. Therefore, adult children are particularly important for facilitating support and inclusion for residents through other ties such as staff members or wider communities. However, these relationships can also become ambiguous when the residents' expectations of the familial role is not fulfilled, or if residents feel restricted by their children's decisions. This ambiguity not only created tension but meant that residents were less likely to make requests of their children and therefore were restricting their support networks and options for resources. Hillcoat-Nallétamby and Phillips (2011) found similar relationships in informal care relationships between older people and their children, which often resulted in less autonomy for the older people, thus adding to their experience of isolation.

There is a perception that older people living in $\mathrm{CHs}$ will have other residents and staff members to talk to, which could reduce the likelihood of loneliness (Dickens et al., 2011). Previous research has found that residents can, and do, make friendships in $\mathrm{CHs}$ (Brown-Wilson, 2008), however, this study found that no resident made a new friend with another resident in the $\mathrm{CH}$. Residents did not want to interact with other residents because they did not want to be associated with people living with dementia, and residents had health issues preventing them from interacting often. This perhaps speaks to research which found that residents who made friends in assisted living housing tended to make friends with people of similar "cognitive status" (Abbott \& Pachucki, 2016). Given that $70 \%$ of $\mathrm{CH}$ residents are estimated to have dementia in the UK (Alzheimer's Society, 2020), and residents are now arriving in $\mathrm{CHs}$ far later in their dementia journey, the creation of meaningful relationships between residents is less likely. This is concerning as friendships with other residents are an untapped source of informal support which residents could benefit from by being able to relate their experiences with people who are going through similar changes to them (Clare et al., 2008). Within $\mathrm{CHs}$, older people eat together multiple times a day, spend time doing activities together and sometimes visiting local areas. Thus, these results bolster the findings of Torres (2019) which discussed how older people created "elastic ties" with people they did not know well, which resulted in them regularly sharing personal information and socialising with these people, but not considering them as confidents. With reference to this study, this could illustrate how fellow residents were treated by the participants as, despite spending extended periods of time in each other's company, residents tended not to want to nominate each other for support. CH staff can only do so much to encourage relationships between residents, however, more research into why friendships are less likely to be created in $\mathrm{CHs}$ and what can be done to encourage this potential source of support is needed.
The lack of staff nominations for support is particularly concerning for the $\mathrm{CH}$ industry as they aim towards PCC frameworks which encourage personal relationships between staff and residents where staff know the likes and dislike of residents, have a knowledge of their background, and understand their wishes and values (Baker, 2015). To learn this information, staff and residents are encouraged to build meaningful, reciprocal relationships with one another (Brown-Wilson, 2008). If these approaches to care were succeeding in $\mathrm{CHs}$, we would expect to see supportive relationships between residents and staff, as well as residents being more involved in $\mathrm{CH}$ life.

Staff relationships that went beyond practical care tasks often took extended time (outside of care tasks) to emerge but resulted in more trusting relationships. Further, residents who had positive relationships with staff tended to feel that the staff were connected to and knew their families. In particular, the work of Brown-Wilson (2008) discusses the importance of staff, residents, and families working together to facilitate better care. She argues that reciprocal and responsive relationships result in the most positive experiences for all stakeholders. Further evidence-based recommendations of past research include that staff should consider families as partners and experts in their residents' care to provide the best care (Davies \& Nolan, 2006). Furthermore, Killett et al. (2016) found that the best care was displayed in $\mathrm{CH}$ s where residents, families and staff worked together, and there was a sense of community in the $\mathrm{CH}$. They provide examples of when staff really showed they cared about both residents and relatives, or when staff were more transparent about their day-to-day work and, therefore, residents and relatives were more understanding of the staff's time and practice. Thus, the current and previous research would suggest that staff members should be considering how to support family members and should include them in the care of their loved one, to create better day-to-day living for residents.

In many ways, the integration of network analysis and thematic analysis allowed a deeper exploration of complex relations within $\mathrm{CHs}$ and as such gives a more nuanced understanding of social relations in $\mathrm{CHs}$. For example, this study defined, and captured, strong and weak ties through residents' descriptions of connections (type of support provided, closeness, and density) and relationships with supportive actors (qualitative descriptions). However, during analysis this was difficult to untangle given that ties that would be traditionally "weak" were sometimes integrated with "strong" ties, as well as described as providing supports traditionally from strong ties. Thus, although my operationalisation of ties strength was not ideal for defining firm distinction between strong and weak, it perhaps reflects the lack of duality between these two concepts.

Moving into a $\mathrm{CH}$ for the increased support of care needs should not limit or stop older people having access to a varied support network. Supportive relationships are 
key to improving and maintaining the wellbeing of residents, and $\mathrm{CHs}$ should promote and invest in these relationships to ensure that future residents receive the support they need to thrive.

\section{Acknowledgments}

I would like to thank Dr Liz Forbat for her guidance, feedback, and encouragement during the writing of this article.

\section{Conflict of Interests}

The author declares no conflict of interests.

\section{References}

Abbott, K. M., \& Pachucki, M. C. (2016). Associations between social network characteristics, cognitive function, and quality of life among residents in a dementia special care unit: A pilot study. Dementia, 16(8), 1004-1019.

Age UK. (2019). Later life in the United Kingdom 2019. https://www.ageuk.org.uk/globalassets/age-uk/ documents/reports-and-publications/later_life_uk_ factsheet.pdf

Alzheimer's Society. (2020). Facts for the media. https:// www.alzheimers.org.uk/about-us/news-and-media/ facts-media

Baker, C. J. (2015). The PEARL program: Caring for adults living with dementia. Nursing Standard, 30(5), 46-51.

Bowling, A. (1994). Social networks and social support among older people and implications for emotional well-being and psychiatric morbidity. International Review of Psychiatry, 6(1), 41-58.

Braun, V., \& Clarke, V. (2020). One size fits all? what counts as quality practice in (reflexive) thematic analysis? Qualitative Research in Psychology, 12(8), 1-25.

Brooker, D., \& Latham, I. (2015). Person-centred dementia care: Making services better with the VIPS framework. Jessica Kingsley Publishers.

Brown-Wilson, C. (2008). Using relationships to develop practice that values the contribution of older people, families and staff. International Journal of Older People Nursing, 3(4), 274-277.

Canham, S. L., Battersby, L., Fang, M. L., Sixsmith, J., Woolrych, R., \& Sixsmith, A. (2017). From familiar faces to family: Staff and resident relationships in long-term care. Journal of Aging and Health, 29(5), 842-857.

Cheng, S. (2009). The social networks of nursing-home residents in Hong Kong. Ageing and Society, 29(2), 163-178.

Clare, L., Rowlands, J., Bruce, E., Surr, C., \& Downs, M. (2008). The experience of living with dementia in residential care: An interpretative phenomenological analysis. The Gerontologist, 48(6), 711-720.
Coleman, J. S. (1988). Social capital in the creation of human capital. American Journal of Sociology, 94(2), 95-120.

Cook, G. (2006). The risk to enduring relationships following the move to a care home. International Journal of Older People Nursing, 1(3), 182-185.

Cornwell, B., Laumann, E. O., \& Schumm, L. P. (2008). The social connectedness of older adults: A national profile. American Sociological Review, 73(2), 185-203.

Crossley, N., Bellotti, E., Edwards, G., Everett, M. G., Koskinen, J., \& Tranmer, M. (2015). Social network analysis for ego-nets: Social network analysis for actorcentred networks. SAGE.

Davies, S., \& Nolan, M. (2006). 'Making it better': Selfperceived roles of family caregivers of older people living in care homes: A qualitative study. International Journal of Nursing Studies, 43(3), 281-291.

De Jong Gierveld, J., \& Hagestad, G. (2006). Perspectives on the integration of older men and women. Research on Aging, 28(4), 627-637.

Dewing, J. (2007). Participatory research: A method for process consent with persons who have dementia. Dementia, 6(1), 11-25.

Dickens, A. P., Richards, S. H., Greaves, C. J., \& Campbell, J. L. (2011). Interventions targeting social isolation in older people: A systematic review. BMC Public Health, 11(1), 647-665.

Forsman, A. K., Schierenbeck, I., \& Wahlbeck, K. (2011). Psychosocial interventions for the prevention of depression in older adults: Systematic review and meta-analysis. Journal of Aging and Health, 23(3), 387-416.

Granovetter, M. S. (1973). The strength of weak ties. American Journal of Sociology, 78(6), 1360-1380.

Granovetter, M. S. (1985). Economic action and social structure: The problem of embeddedness. American Journal of Sociology, 91(3), 481-510.

Grenade, L., \& Boldy, D. (2008). Social isolation and loneliness among older people: Issues and future challenges in community and residential settings. Australian Health Review, 32(3), 468-478.

Hillcoat-Nallétamby, S., \& Phillips, J. E. (2011). Sociological ambivalence revisited. Sociology, 45(2), 202-217.

Holstein, B. (2014). Mixed methods social networks research: An introduction. In S. Dominguez \& B. Holstein (Eds.), Mixed methods social networks research. Design and applications (pp. 3-34). Cambridge University Press.

House, J., \& Khan, R. (1985). Measures and concepts of social support. In S. Cohen \& S. L. Syme (Eds.), Social support and health (pp. 83-108). Academic Press.

Killett, A., Burns, D., Kelly, F., Brooker, D., Bowes, A., La Fontaine, J., Latham, I., Wilson, M., \& O'Neill, M. (2016). Digging deep: How organisational culture affects care home residents' experiences. Ageing \& Society, 36(1), 160-188.

Kitwood, T. (1997). The experience of dementia. Aging \& Mental Health, 1(1), 13-22. 
Langford, C. P. H., Bowsher, J., Maloney, J. P., \& Lillis, P. P. (1997). Social support: A conceptual analysis. Journal of Advanced Nursing, 25(1), 95-100.

Lüscher, K. (2002). Intergenerational ambivalence: Further steps in theory and research. Journal of Marriage and the Family, 64(3), 585-593.

McCallister, L., \& Fischer, C. S. (1978). A procedure for surveying personal networks. Sociological Methods \& Research, 7(2), 131-148.

National Institute for Health and Care Excellence. (2019). Mental wellbeing of older people in care homes. https://www.nice.org.uk/about/nice-communities/ social-care/tailored-resources/mwop

National Institute for Health Research. (2021). Enrich. https://enrich.nihr.ac.uk

Nicholson, N. R., Jr. (2009). Social isolation in older adults: An evolutionary concept analysis. Journal of Advanced Nursing, 65(6), 1342-1352.

Perry, B. L., Pescosolido, B. A., \& Borgatti, S. P. (2018). Egocentric network analysis: Foundations, methods, and models. Cambridge University Press.

Roberts, T., \& Bowers, B. (2015). How nursing home residents develop relationships with peers and staff: A grounded theory study. International Journal of Nursing Studies, 52(1), 57-67.

Scottish Government. (2016). The Scottish index of multi- ple deprivation. https://www.gov.scot/publications/ scottish-index-multiple-deprivation-2016

Social Care Institute for Excellence. (2021). Mental Capacity Act 2005 training courses. https://www. scie.org.uk/training/mentalcapacityact

Torres, S. (2019). On elastic ties: Distance and intimacy in social relationships. Sociological Science, 6(10), 235-263.

Victor, C. R. (2012). Loneliness in care homes: A neglected area of research? Aging Health, 8(6), 637-646.

Villar, F., Serrat, R., Bilfeldt, A., \& Larragy, J. (2021). Older people in long-term care institutions: A case of multidimensional social exclusion. In K. Walsh, T. Scarf, S. Van Regenmortel, \& A, Wanka. (Eds.), Social exclusion in later life. International perspectives on aging (pp. 297-309). Springer.

Wald, A. (2014). Triangulation and validity of network data. In B. Holstein \& S. Dominguez (Eds.), Mixed methods social networks research: Design and applications (pp. 65-89). Cambridge University Press.

Wellman, B. (1981). Applying network analysis to the study of support. Social Networks and Social Support, 4(1), 171-200.

White, H. C. (2008). Identity and control: How social formations emerge. Princeton University Press.

\section{About the Author}

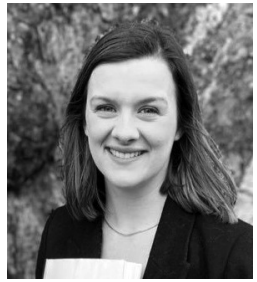

Jennifer M. Ferguson (PhD) is an ESRC-funded research fellow at the University of Stirling. Her research explores the systematic patterns observed in the social networks of older people with an overall aim to improve the wellbeing and social inclusion of older people living in care homes. She specialises in mixed-method egocentric network analysis to explore the complexity of relationships within networks and uses this methodology to critically examine the impact of care policies and practice on residents' social relationships. 